\title{
ADDRESSES
}

\section{DEVELOPMENT OF CHEMICAL INDUSTRIES IN SOUTHERN CALIFORNIA SINCE JANUARY I, I9I6 1}

\author{
BY ARTHUR W. KINNEY
}

Industrial Commissioner, Los Angeles Chamber of Commerce

An eminent authority says that the measure of a country's appreciation of the value of chemistry in its material development and the extent to which it utilizes this science in its industries, generally measure quite accurately the industrial progress and prosperity of that country.

The year I 9 I 6 has been the most notable year in the history of Southern California in the amount invested in chemical manufacturing enterprises and in the number of new products exploited. Millions of dollars have been expended in modern plants and more than twenty new products have been developed, samples of which are on display at the industrial bureau of the Chamber of Commerce.

Very few of the people of this region appreciate the opportunities and possibilities which prevail here with regard to an important chemical industry. The great European war, which has curtailed and in many instances completely shut off the old supply of chemicals heretofore imported, has caused an enormous awakening throughout our nation, and has been productive of a large amount of chemical research and investigation. The reason for this is apparent, in view of the statement that the volume of trade and manufacture in the United States at the present time, which is directly dependent on the needs of the chemist, is about $\$ 7,000,000,000$ per annum. As the months roll by it is being demonstrated that American chemical manufacturers have the brains and ability to produce nearly all substances which have heretofore been imported. In view of the authoritative statement that in California there exists a wider diversity of the crude chemical materials of nature than in any similar area of the world, it is not strange that this section is playing such a prominent part in the exploitation of new materials and is doing its full share in the building up of a great American chemical industry.

In this article we shall dwell only upon those Southern California enterprises which have commenced operation since January I, 1916.

During the year the Hercules Powder Company has come into the field and invested $\$ I, 500,000$ at Chula Vista, below San Diego City proper. The improvements consist of barges and harvesters, two of the latter costing $\$ 45,000$ and $\$ 60,000$, respectively; a pier 2300 feet long, a floating machine shop, I 56 tanks holding 50,000 gallons each and 9 holding 400,000 gallons each. There are housings for an intricate mass of machinery, engines, electrical equipment, laboratories, evaporators, separators, presses, conveyors, etc. Potassium, iodine and acetone are taken out of solution by processes known only to the chemists, of which there are sixteen. Power is supplied by six batteries of Edgemoor boilers, with a capacity of 2700 horse power. The plant covers an area of several acres.

At the harbor district of Los Angeles five good-sized kelp products concerns have begun operations during the present year--the National Kelp Potash Company, Oceanic Engineering Company, Pacific Products Company and International Potash Properties Company of Long Beach, and the Diamond Match Company at Wilmington. The product of the latter company is used by the great plants of the Diamond Match Company of national fame. After considerable investigation the Department of Agriculture has decided to locate and operate at Summerland, Santa Barbara County, an experimental kelp products plant which will have a capacity of 200 tons of kelp per day.

1 Reprinted from the Los Angeles Sunday Times, December 17, 1916.
This institution will cost approximately $\$ \mathrm{r} 75,000$, and will give the potash industry a thorough tryout.

\section{POTASH INDUSTRIES}

The American Trona Corporation, of which Baron A. de Rapp is president, has completed during the year two costly refineries, one at Trona, Searles Lake, San Bernardino County, where the raw material is obtained, and the other at Los Angeles Harbor, where the concentrated salts are to be refined.

The buildings at Searles Lake, extending a distance of onethird of a mile, are of fireproof construction and include laboratories, engineers' building, auxiliary building, evaporator building, machine shops, power plant equipped with four 500 -horsepower Babcock \& Wilcox boilers, spray pond, restaurant, offices, sleeping quarters, physicians' quarters with hospital and operating-room and cottages for married employees. A supply of fresh water is brought from the mountains sixteen miles distant.

The buildings of the plant at Los Angeles Harbor are also of fireproof construction and include a refinery building, office building, laboratory, warehouse, machine shop and power plant containing two 5oo-horse-power Babcock \& Wilcox boilers.

The American Trona Company is now shipping potassium chloride from the Searles Lake plant. Other probable products from this and the harbor plants are caustic potash, permanganate of potash, bicarbonate of potash, borax, sodium carbonate, chloride and sulfate.

Another large chemical enterprise which will handle similar products is that of the Solvay Process Company, an $\$ 18,000,000$ corporation, now erecting a modern plant at Borosolvay, Searles Lake. The buildings of this concern include a power plant, evaporator building, machine shop, crystallization building, warehouses, clubhouse, commissary and cottages. The Solvay Process Company is the discoverer of the process for manufacturing caustic soda and now operates large chemical plants at Syracuse, N. Y., and other cities.

Other sources of potash exploited during the year have been the plant of the Riverside Portland Cement Company and various Southern California beet-sugar factories. From the firstmentioned source many thousand dollars' worth were obtained as a by-product.

At San Diego the Lower California Chemical Company is erecting the first unit of a plant which will be devoted to the making of orcein dyes, using as a raw material the orchilla weed, a moss found growing in vast quantities along the western coast of Lower California. It is claimed that these dyes can be produced cheaper than the imported article and are equal, if not superior, to the same.

\section{DYESTUFFS}

Another dyestuff enterprise of the year is the Internal Dye Products Company, which has recently equipped a new plant at Vernon. This company is backed by Los Angeles men and will engage in the manufacture of aniline dyes, using as raw materials the by-products of the local oil refineries and gas plants.

At Corona, Riverside County, the Citrus By-Products Company, a coöperative organization composed of various members of the California Fruit Growers' Exchange, has been in active operation manufacturing citric acid from cull lemons, having used this year over 2000 tons of the latter. The principal source of this commodity has been Italy, where in some sections the industry consumes from one-third to the whole of the lemon crop.

During the year three new concerns have gone into the manufacture of strontium nitrate. This chemical is largely employed in the manufacture of red fire and is used by manufacturers 
of fireworks and railway signals. The raw material comes from San Bernardino and Imperial Counties. Prior to the war practically all this commodity was imported from Europe. The new companies in operation are F. G. Mortimer Company, at Vernon; Long Beach Chemical Company, and Southern Reduction Company, both at Long Beach. The latter concern also operates a new plant at Vernon, where it is making a highgrade of chloride of lime and chlorine. Another new enterprise at Vernon is the California Chemical Company, which is now erecting a plant for the manufacture of orchard sprays.

The Linde Air Products Company, which operates factories in twenty or more American cities, has just completed in Los Angeles a modern plant for the manufacture of oxygen gas.

During the year the Grand Canyon Lime and Cement Company has equipped and placed in operation a complete establishment for the manufacture of hydrated lime.

The Industrial Bureau has been advised of the erection of a factory at Escondido which will handle eucalyptus lumber from the large groves in that vicinity. One of the important by. products will be eucalyptus oil, now largely used in manufacturing pharmaceutical preparations.

\section{OTHER NEW PRODUCTS}

Other new products of the year are molybdic acid salts, made by the Rose Chemical Company and American Alloy and Chemical Company, tungstic acid by the Tungsten Mines Company, and oxide of antimony by the Western Metals Company. In addition to the foregoing there have been made in limited quantities molybdic oxide, ammonium molybdate, ferro-tungsten, ferro-manganese, ferro-vanadium, ferro-molybdenum and strontium hydrate. Crude sulfur from Nevada has found a ready sale among our local manufacturers.

Of more than passing importance has been the exhaustive investigation of the Rittman refining process made by the Independent Oil Producers' Agency and the statement made that while fairly good results have been obtained, the installation of a small plant more closely adapted to California requirements is being considered.

This has been a remarkable year in chemical development, made so largely through the incentive of high prices, and the things accomplished must be gratifying indeed to our business men and chemists. We have here raw materials of great variety; we have by-products almost without number. Adequate research work and the solving of the problem of keeping down the manufacturing costs of production should enable us to convert these raw products into commodities that will eventually bring hundreds of millions of dollars to this region.

Los ANGeles, CALIFORNIA

\section{INITIATION OF EXPLOSIONS ${ }^{1}$}

By WALTER ARTHUR

Received February 2, 1917

Just when gunpowder was first known is a matter of most vague conjecture, but its use was recorded many centuries ago. Its advent into the world brought most marvelous changes into political matters, and at present, is playing the most important rôle in the greatest of all human activity. Accompanying the use of powder and explosives, and closely allied with their development, is another and most important problem-the initiation of the burning or explosion. Powder and explosives afford us a convenient means of doing work, if the energy represented can be made use of at a desired moment and in a manner perfectly safe to those using them. The character of the explosion is dependent upon the efficiency of the method of ignition. Hence the importance of the question of initiation.

Until quite recent times, black powders or kindred mixtures were the only explosives in use; the energy contained was liberated by the burning of the mixture. This required only the

1 Presented before the January Meeting of the Philadelphia Section of the American Chemical Society, January 18, 1917. minutest flame to start the ignition, as the particles of the various components were extremely finely divided, and a very small amount of heat was sufficient to raise them to the ignition point. The method of ignition was to fill with powder a small opening which led into the powder chamber, and by means of a flame or spark, ignite this powder train from the outside. This was the old method of the match locks and flint locks. Most of the old cannons we see in our parks and public places were of this type.

\section{PRIMERS}

In 1799 , Howard discovered the substance we know as mercury fulminate. Its ability to fire gunpowder gave rise about the year 1815 to the development of the percussion cap. This is the beginning of what might be termed internal ignition in contradistinction to the earlier method which we may style external ignition.

The percussion cap may be briefly described as a small metal capsule containing a small amount of mercury fulminate, or mercury fulminate mixture, or other mixture with similar properties. This was used by placing it over the ends of a small tube which lead to the powder chamber. When struck a sharp blow, the mixture detonated, giving rise to considerable heat, thus igniting the powder. This method of ignition for firearms was in common use until very recent times and is occasionally seen to-day. The significance of this invention was as great as the discovery of guncotton or smokeless powder. It made the ordinary firearms much more effective by relieving the gunner of any anxiety as to whether he had powder in his pan. It permitted of ready use and made the arm independent of the weather. The combining of the projectile, powder charge and priming charge into one cartridge, has made our breechloading firearms and machine guns possible.

There are a number of methods of internal ignition; all of them are much alike. In some substances, as in light ammunition, where a cartridge case with a thin head can be used, the priming mixture is placed in the rim of the head. This rim is struck a sharp blow by the firing pin where it is desired to ignite the powder; hence the so-called "rim fire." In most instances the priming mixture is placed in a small cup and inserted in a chamber in the head of the cartridge case, the firing of the priming charge being done by crushing the priming mixture between the cup bottom and the anvil. Many manufacturers of such ammunition place the anvil in the cup, but others make the anvil a part of the cartridge case, the result of the explosion of the primer pellet being a flame of considerable length and intense heat. The primer cup, being held securely in its chamber, allows no escape of flame except through a vent into the powder charge.

The length and heat of the primer flame will determine very largely the character of explosion in the cartridge case. If the flame be short and the temperature not very high, only a portion of the powder may be burned before the projectile leaves the muzzle of the gun. This, of course, lowers the pressure behind the projectile; as a result, a lower velocity of the projectile is obtained. On the other hand, if the primer flame be long and the temperature high, all of the powder may be fired.

The number of mixtures proposed for use in percussion caps and primers is legion; four of these are as follows:

$21.9 \%$ Sulfur (flowers)
$30.8 \%$ Antimony Sulfide
$47.2 \%$ Potassium Chlorate
$35.01 \%$ Ground Glass
$28.01 \%$ Mercury Fulminate
$14.00 \%$ Potassium Chlorate
$1.97 \%$ Shellac
$21.00 \%$ Antimony Sulfide

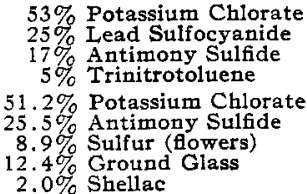

It will be seen that either potassium chlorate or mercury fulminate is to be found in each of them.

In order to increase the sensitiveness of the primer, an abra- 